\title{
O ENSINO DE GRAMÁTICA E AS ARTICULAÇÕeS TEÓRICO- METODOLÓGICAS DA PRÁTICA DE ANÁLISE LINGUíSTICA
}

\author{
THE TEACHING OF GRAMMAR AND THE THEORETICAL-METHODOLOGICAL \\ ARTICULATIONS OF THE PRACTICE OF LINGUISTIC ANALYSIS
}

\author{
Andréia Rutiquewiski Gomes | Lattes | andreiaruti@gmail.com \\ Universidade Tecnológica Federal do Paraná
}

\author{
Sueder Souza | Lattes | swedersouza@gmail.com \\ Universidade Tecnológica Federal do Paraná
}

\begin{abstract}
Resumo: Este artigo discute aspectos teórico-práticos relacionados ao ensino de gramática na educação básica brasileira. Parte-se de uma discussão acerca dos diferentes tipos de gramática que podem ser considerados quando se trata do trabalho com língua materna para, em seguida, chegar aos princípios da prática de Análise Linguística (AL), compreendida como uma atividade de reflexão sobre as diferentes dimensões que compõem a língua em uso. A AL oferece uma proposta de ensino em consonância com uma visão de linguagem interacionista e, pode, portanto, contribuir para o desenvolvimento das habilidades linguísticas dos sujeitos. Autores como Bakhtin (2006, (2013), Antunes (2003, 2007, 2014), Bezerra e Reinaldo (2013), Wachowicz (2010) e Mendonça (2006), constituem a base teórica deste estudo. Também as recomendações oficiais de ensino (BRASIL, 1998, 2000, 2002, 2006) são consideradas.
\end{abstract}

Palavras-chave: Ensino de Língua Materna; Gramática(s); Análise Linguística.

\begin{abstract}
This article discusses theoretical-practical aspects related to grammar teaching in Brazilian Basic Education. It starts with a discussion about the different types of grammar that must be considered when working with mother tongue and then to arrive at the principles of the practice of Linguistic Analysis (LA), understood as an activity of reflection about the different dimensions that make up language in use. The LA offers a teaching proposal in line with an interactionist view of language and, therefore, can contribute to the development of the linguistic abilities of the subjects. Bakhtin (2006, 1929), Antunes (2003, 2007, 2014), Bezerra and Reinaldo (2013), Wachowicz (2010) and Mendonça (2006) constitute the theoretical basis. The official teaching recommendations (BRAZIL, 1998, 1999, 2000, 2002, 2006) are considered.
\end{abstract}

Keywords: Mother tongue education; Grammar(s); Linguistic Analysis. 


\title{
Considerações iniciais
}

Ao se falar em ensino de Português na educação básica, a primeira questão a ser lembrada é que a toda forma de trabalho escolar há uma concepção de língua subjacente. Segundo os documentos oficiais vigentes no país (BRASIL, 1998, 2000, 2002, 2006), a visão de linguagem que deve nortear as práticas pedagógicas é a interacionista (círculo de Bakhtin). Segundo os postulados dessa abordagem teórica:

\begin{abstract}
A verdadeira substância da língua não é constituída por um sistema abstrato de formas lingüísticas nem pela enunciação monológica isolada, nem pelo ato psicofisiológico de sua produção, mas pelo fenômeno social da interação verbal, realizada através da enunciação ou das enunciações. A interação verbal constitui assim a realidade fundamental da língua (BAKHTIN, 2006, p. 125).
\end{abstract}

Como se observa, de acordo com Bakhtin, a noção de língua está estritamente ligada aos aspectos sociais, pois seu domínio permite a efetiva participação do indivíduo no meio em que está inserido. Logo, para o autor, se a linguagem não estiver associada às interações sociais, ela perde sua peculiaridade essencial.

A interação verbal, conforme as ideias bakhtinianas, realiza-se por meio das enunciações. Os enunciados, por sua vez, organizam-se em gêneros textuais (já que cada esfera social possui seus tipos relativamente estáveis) e materializam-se em textos orais ou escritos. Assim, o enunciado é considerado a unidade real da comunicação discursiva e só por meio dele é que se pode compreender a natureza linguística.

Sobre o interacionismo, Travaglia (2009) destaca que essa concepção considera a completa interação social entre os interlocutores e entende a língua como parte constituinte do sujeito. Os aspectos sociais, históricos e coletivos do indivíduo entram em jogo, ou seja, estão em recíproca constitutividade e são importantes para o processo de significação. Para o autor:
A linguagem é, pois, um lugar de interação humana, de interação comunicativa pela produção de efeitos de sentido entre interlocutores, em uma das situações de comunicação e em um contexto sócio- histórico e ideológico. Os usuários da língua ou interlocutores interagem enquanto sujeitos que ocupam lugares sociais e "falam" e "ouvem" desses lugares de acordo com formações imaginárias (imagens) que a sociedade estabeleceu para tais lugares sociais. (TRAVAGLIA, 2009, p. 23).

Seguindo esses caminhos teóricos, os documentos oficiais (BRASIL, 1998, 2000, 2002, 2006) organizam as bases norteadoras para o ensino de língua materna e suge- 
rem práticas voltadas para a interação linguística em que o Português seja compreendido como heterogêneo, multifacetado, vivo e dinâmico. A leitura, a escrita e a oralidade passam a ser centrais em todo o processo e a reflexão sobre os aspectos gramaticais necessita permear tais práticas. Desse modo, não há sentido o ensino da gramática de modo mecânico ou desarticulado dos usos sociais linguísticos.

É necessário destacar aqui que é exatamente por conta do ensino equivocado de gramática repetitiva, descontextualizada, metalinguística, que se arrasta infinitamente pelas escolas brasileiras, que ainda há a discussão sobre o fato da sua presença ou não em sala de aula. Sobre essa questão, Antunes (2007, p. 21) aponta que as controvérsias acerca do ensino de língua "vão desde a crença ingênua de que, para se garantir eficiência nas atividades de falar, ler e de escrever, basta estudar gramática (quase sempre nomenclatura gramatical), até a crença, também ingênua, de que não é para se ensinar gramática”.

Pretende-se, portanto, neste artigo, mostrar que a gramática pode sim estar nas aulas de língua materna. Contudo, é preciso atentar ao tipo de gramática que é necessária à interação linguística social e ao modo de abordá-la em classe. Assim, a partir dessa afirmação, têm-se dois grandes propósitos: (i) apresentar que gramática(s) pode(m) estar ao alcance dos estudantes e; (ii) discutir sobre o melhor modo de investi-la(s) na educação básica. Para alcançar esses objetivos, divide-se este texto em três partes. Inicialmente, são abordadas algumas das principais concepções de gramática existentes, delimitando suas contribuições e limitações ao ensino de língua materna. Em seguida, explicita-se a análise linguística (AL) como uma das maneiras de se trabalhar com a(s) gramática(s) no ambiente escolar e discutem-se seus princípios elementares. Por fim, são tecidas algumas conclusões e questionamentos finais. Trata-se de um estudo de caráter documental e bibliográfico, que visa à exploração e ao aprofundamento do tema em questão.

\section{Gramática ou gramáticas?}

Gramática é um termo complexo, recheado de relações e significações. Logo, para serem tecidas considerações acerca da gramática e do ensino, é preciso, primeiramente, ter em mente a gama de acepções que estão envolvidas sob esse rótulo. Antunes (2007), no excerto abaixo, oferece uma amostra dessas variadas compreensões:

a) das regras que definem o funcionamento de determinada língua, como em: "a gramática do português", nessa acepção, a gramática corresponde ao saber intuitivo que todo falante tem de sua própria língua, a qual tem sido chamada de "gramática internalizada"; b) das regras que definem o funcionamento de determinada norma, como em: "a gramática da 
norma culta”, por exemplo; c) de uma perspectiva de estudo, como em: "a gramática funcionalista"; ou de uma tendência histórica de abordagem, como em: "a gramática tradicional", por exemplo; d) de uma disciplina escolar, como em: "aulas de gramática"; e) de um livro, como em: "a gramática de Celso Cunha”. (ANTUNES, 2007, p. 25-26).

Pelo fragmento acima, é possível observar que não são poucas as visões de gramática existentes. No ensino de língua materna, algumas delas são bem relevantes, visto que, segundo os estudiosos e as recomendações governamentais, podem fazer parte da aula de Português.

A primeira concepção é a de gramática internalizada que, como o próprio nome sugere, está ligada ao fato de que todo falante possui um conhecimento implícito que lhe permite construir e entender sentenças em sua língua. Depreende-se, outrossim, que todo falante possui uma gramática, um conjunto de regras interiorizadas acerca da sua língua. De acordo com Antunes:

Se uma criança diz "minhas colegas e meus colegos", "um algodão" e "um algodinho", é porque já domina as regras morfossintáticas de indicação do masculino e do feminino, bem como as regras de indicação do aumentativo e do diminutivo em português. Ou seja, já sabe esses pontos da gramática. Da gramática geral que regula o funcionamento da sua língua: por exemplo, se a língua tem artigos, se tem preposições, se adota flexões (de número, de gênero, de grau, de tempo etc. e para que tipos de palavras), que posições as palavras podem ocupar na frase, que funções podem ser atribuídas a essas posições, etc. (ANTUNES, 2007, p. 27).

Essa gramática é aprendida naturalmente pela criança durante o processo de aquisição da linguagem. Logo, quando chega ao período escolar, o estudante já tem internalizada a sua língua e esse conhecimento precisa ser considerado pelos docentes, o que, de fato, não acontece. Na maioria das vezes, os professores ignoram totalmente esse saber e ensinam o português como se os alunos nada soubessem da língua.

Isso é um equívoco, pois mesmo que a variedade que o aluno traz seja desprestigiada socialmente, sabe-se que ela possui uma riqueza estrutural e funcional enorme, do mesmo modo que qualquer outra. Nas palavras de Antunes (2007, p. 27), "existe a ideia simplista e ingênua de que apenas a norma culta segue uma gramática. As outras normas funcionam sem gramática. Movem-se à deriva. Ora, toda língua - em qualquer condição de uso - é regulada por uma gramática”.

A ideia é então que o professor desfaça preconceitos e passe a considerar a gramática internalizada dos estudantes. Nesse sentido, o objetivo do ensino precisa ser revisto 
e o docente pode trabalhar com o intuito de tornar conscientes as regras implícitas da língua e procurar refletir sobre elas. Pode-se também aprimorá-las aos usos em diferentes contextos, estimulando e desenvolvendo verdadeiramente as habilidades linguísticas. A partir desses pressupostos, o docente pode capacitar o aluno ao uso ciente e criativo dos inúmeros recursos e estratégias linguísticas disponíveis nas diversas variedades do português.

A segunda e mais polêmica acepção é a de gramática prescritiva/normativa. Essa noção está fortemente ligada à gramática tradicional, que segundo Görski e Moura (2011, p. 63), "fundamenta sua análise em textos literários escritos, tomando-os como modelo de correção". Essa gramática inspirou a normativa que, por sua vez, "pode ser definida como conjunto de regras que devem ser seguidas. $\mathrm{O}$ uso linguístico que atende a essas regras é dito 'correto'; o que não obedece às regras é taxado de 'errado' (GÖRSKI; MOURA, 2011, p. 62-63)".

Como este tipo de gramática direciona seu olhar apenas ao conjunto de regras da norma padrão ${ }^{2}$, deixa de lado todas as demais variedades do Português do Brasil. Desse modo, nessa abordagem, são desconsiderados todos os aspectos históricos, sociais e culturais aos quais estão ligados os falantes do Português. Isso gera um problema de grande proporção, pois não se assume a rica heterogeneidade linguística do Brasil e, por consequência, se o docente centra suas aulas somente nessa visão, está contribuindo para uma padronização excessiva e não realística do Português, pois as regras defendidas por esse tipo de gramática são compreendidas efetivamente como um tipo de lei uniformizadora.

Outro problema relacionado à gramática normativa é que ela apresenta muitas definições e metalinguagens, o que é desgastante e inútil ao aluno, pois não há propósito comunicativo algum na decoreba de rótulos. Defende-se, portanto, que as atividades de ensino estejam direcionadas para diferentes aspectos linguísticos e extralinguísticos, ou seja, as análises da língua em uso devem voltar-se a fenômenos semânticos, pragmáticos, sintáticos, morfológicos, discursivos, estilísticos, visuais, sonoros etc. O que tem que entrar em jogo é a compreensão do texto e o seu funcionamento (como se constitui, seus recursos, etc.). As próprias diretrizes salientam que, por mais que seja necessário, em alguns momentos, atentar a tópicos da norma padrão, o professor não pode priorizar conceituações. Até mesmo para o ensino médio, as Orientações Educacionais Complementares

\footnotetext{
${ }^{1}$ Ver também Possenti, 1996, p. 64.

2 Assume-se, aqui, a visão de Faraco (2004) acerca da diferenciação de norma culta e norma padrão. A norma culta refere-se aos usos reais linguísticos em situações formais. Já, a norma padrão, se concentra em padronizar a língua, considerando o que é diferente um “erro". Essa é a norma apresentada pelas gramáticas de cunho normativo-prescritivo.
} 
aos Parâmetros Curriculares Nacionais $(\mathrm{PCN}+)$ sugerem "uma certa relativização da nomenclatura e dos conteúdos tradicionais [...]”, considerando significativa a internalização de "determinados mecanismos e procedimentos básicos ligados à coerência e coesão do que memorize, sem a devida apreensão de sentido, uma série de nomes de orações subordinadas ou coordenadas (BRASIL, 2002, p. 70-71)”.

Apesar desses imbróglios apontados sobre o trabalho com a gramática normativa, a escola não pode de modo algum abandonar o ensino da norma culta (sobretudo para a escrita), pois se voltaria ao absurdo de que "vale tudo" em todas as situações sociais. Possenti (1996) já defendia essa posição, procurando mostrar que, mesmo com os problemas normativos, não se pode excluí-los totalmente da escola. Segundo o autor, é preciso compreender que o Português não é exatamente o que está dentro de um compêndio gramatical. Nesse caminho, considera-se aqui que não se pode negar que há tópicos normativos/prescritivos que são necessários às produções textuais (escritas e orais em situações formais). Como exemplo, pode-se citar a concordância, a ortografia, a pontuação, a acentuação e a crase. Nesses casos, é preciso ter acesso à gramática - via atividades, consultas, pesquisas, leituras - para conhecer as normas que regem esses fenômenos e, dessa maneira, ampliar a competência do estudante, capacitando-o para o uso da língua em situações específicas. Entende-se, portanto, que há aspectos da prescrição linguística que precisam ser levados à sala de aula e a gramática normativa não pode ser completamente esquecida. A questão então é como abordá-la na prática escolar. ${ }^{3}$

A última concepção que será tratada é a de gramática descritiva. Esse tipo de gramática busca registrar e descrever os usos que se faz da língua em sua sincronia, "trabalha com qualquer variedade da língua e não apenas com a variedade culta e dá preferência para a forma oral desta variedade” (TRAVAGLIA, 2009, p. 33). Görski e Moura (2011, p. 65) afirmam que a gramática descritiva apresenta o uso regular e efetivo da língua, no intuito de caracterizar as formas possíveis de expressões existentes, olhando quando e por quem são produzidas determinadas regularidades.

Nessa perspectiva, o erro é somente a ocorrência que não é falada ou escrita nos variados usos sociais da língua em foco. Logo, é fácil compreender que essa visão de gramática propõe uma separação entre o que é erro linguístico e diferença linguística: os erros são as construções que não se encaixam em nenhuma variedade da língua descrita e as diferenças referem-se a formas que divergem de determinado padrão.

Assim, segundo Bezerra e Reinaldo (2013), a gramática descritiva é resultado de fundamentos de determinada corrente de investigação sobre a linguagem, como o com-

\footnotetext{
${ }^{3}$ Este tópico será abordado na próxima seção.
} 
parativismo, o estruturalismo, o gerativismo, etc. Essa visão observa a língua como objeto de estudo científico e a descreve por meio de uma linguagem especializada, caracterizando-se também, por uma metalinguagem ${ }^{4}$. Procura representar a língua como ela é na realidade, ou seja, trabalha diretamente com a língua em que os sujeitos estão imersos, elencando sua estrutura e sistema, atrelado às suas particularidades.

Em vista disso, defende-se que os estudos decorrentes de gramáticas descritivas podem respaldar o ensino de língua materna, não, é claro, no sentido de que se passaria a ensinar e adotar em classe uma gramática advinda da linguística. Entretanto, como essas gramáticas refletem, de modo real, o Português e suas variedades, entende-se que podem respaldar, de modo especial, a preparação docente. Sabe-se que, muitas vezes, o professor iniciante precisa rever e reforçar conhecimentos antes de entrar em sala de aula, assim é melhor que o docente relembre certos aspectos da língua(gem), como, por exemplo, a concepção que mais dá conta atualmente do ensino, ou seja, a interacionista. Com isso, o professor conseguirá promover atividades e discussões pertinentes à língua e seu dinamismo. Também o docente poderá conduzir práticas em que saberá explicar aos alunos as diferenças linguísticas, variações, etc. Ainda, com estudantes mais experientes (final do ensino médio), poderiam ser realizadas pequenas pesquisas ou consultas a tais materiais. Isso também serviria como um respaldo a observações e pesquisas sobre a língua, contribuindo para que a nova geração se livre de preconceitos e compreenda que a língua também é estudada cientificamente.

Antunes (2014, p. 92), sobre esse assunto, afirma que

[...] a contribuição da ciência linguística para o entendimento amplo e científico do fenômeno linguístico é fundamental para o trabalho de quem lida com o ensino. Mais especificamente, saber o que são 'as gramáticas de uma língua', quais suas funções e, ao mesmo tempo, seus limites é estar em condições para, pelo menos, definir prioridades e modos de atender a elas, a fim de não pretender 'tirar leite de pedras'.

Como se percebe, não é possível falar de gramática e ensino, mas sim de gramáticas e ensino. Defende-se, portanto, que essas três gramáticas podem nortear o ensino, dependendo da situação e do objetivo pretendido. Por exemplo, a gramática internalizada pode ser considerada o ponto de partida para as atividades escolares, no sentido de que o docente parte dos conhecimentos dos educandos, levando-os a explicitar as normas

\footnotetext{
${ }^{4}$ Vale destacar que a descrição não é exclusiva da gramática denominada descritiva, pois, por exemplo, até mesmo a gramática tradicional também se vale, em alguns momentos, de descrições. Estas, porém, não são o centro da gramática tradicional.
} 
implícitas da(s) língua(s). Aliada a essa ação, o docente, pode seguir no árduo caminho de ampliar os saberes linguísticos do aluno, preparando-o para futuras e variadas situações sociais. Para isso, os conhecimentos advindos das gramáticas descritivas podem subsidiar o docente na preparação das aulas e na elaboração de atividades. Também, no fluxo das aulas e dos fenômenos linguísticos que apareçam, pode-se levar algumas obras para consulta em grupos ou para respaldo das observações do professor. Por fim, se um dos objetivos da aula de Português é assegurar que o indivíduo compreenda e pratique a norma culta escrita, é necessário que ele perceba, por exemplo, que a palavra juízes tem acento gráfico e juiz não. Para isso, há uma convenção que precisa ser conhecida, logo é necessário recorrer a gramática prescritiva. É importante deixar claro que, com isso, não se defende um retorno ao ensino normativo prescritivo e tradicional. Até porque há inúmeras formas de chegar a um conteúdo como a acentuação gráfica. Uma coisa é o professor chegar na escola, passar inúmeras regras de acentuação e mandar decorar para a prova, outra é partir de textos escritos reais (como os jornais, por exemplo) e analisar as palavras da língua que recebem acento e tentar observar se há alguma lógica nessa regra ou se é uma mera convenção. Nessa situação, o professor parte de um gênero, manifestado em um texto verdadeiramente escrito por alguém numa situação (devendo, assim, atentar ao seu objetivo, público alvo, entre outros) e pode também mostrar, por exemplo, a credibilidade que tem um jornal que atende aos princípios básicos da escrita versus um jornal que apresente falhas visíveis.

Na perspectiva apresentada, respeitar-se-ia a ideia de que "a linguagem, na escola, passa a ser objeto de reflexão e análise, permitindo ao aluno a superação e/ ou a transformação dos significados veiculados” (BRASIL, 2000, p. 6-7). Logo, a escola brasileira poderia sair do limbo a que está presa, deixando de abordar apenas aspectos formais e desarticulados da língua para que ela passasse a ser analisada, observada, investigada (ANTUNES, 2009).

Dar-se-á, na seção seguinte, início a uma discussão sobre como se pode ensinar gramática(s) na escola.

\section{0 ensino de gramática pelo viés da Análise Linguística}

Atualmente, não se fala em trabalho com a gramática isolada, ou seja, com objetivos voltados a ela mesma. Não se recomendam atividades de memorização de regras ou conceitos. A gramática de uma língua precisa ser estudada a partir do lugar em que ela ocorre, ou seja, dentro de usos reais linguísticos (interações sociais). Também não pode ser decorada, mas observada e analisada. 
É muito fácil de se observar que o ensino tradicional não dá conta dessa forma de se trabalhar e, portanto, é necessário ampliar as metodologias para o ensino. Muito se tem falado das práticas de análise linguística $(\mathrm{AL})$ nas aulas de língua materna. Essa concepção tem origem nos estudos de João W. Geraldi, em especial na obra $O$ texto na sala de aula (2002 [1984]). Nesse trabalho, o autor propõe as bases para a AL, sugerindo reflexões linguísticas (não somente prescritivas) a partir dos textos produzidos pelos próprios discentes. As repercussões dessa proposta foram muito grandes e acabaram sendo incorporadas, com algumas modificações, aos Parâmetros Curriculares Nacionais (BRASIL, 1998).

A partir da visão fundadora de Geraldi (2002 [1984]), autores como Antunes (2003, 2007, 2009, 2014), Mendonça (2006), Wachowicz (2010), Kemiac e Araújo (2010) e Bezerra e Reinaldo (2013) vêm discutindo, elucidando e aprofundando pressupostos teórico-metodológicos da AL. ${ }^{5}$

Mendonça (2006), num período em que a AL ainda era muito obscura para a maioria dos docentes, trouxe importantes contribuições. A autora faz uma comparação entre ensino de gramática e AL e destaca as principais diferenças entre as duas práticas. Especificamente, Mendonça (2006, p. 206) afirma que o objetivo central da AL é “[...] refletir sobre elementos e fenômenos linguísticos e sobre estratégias discursivas, com o foco nos usos da linguagem." Segundo a autora:

[...] a AL é parte das práticas de letramento escolar, consistindo numa reflexão explícita e sistemática sobre a constituição e o funcionamento da linguagem nas dimensões sistêmica (ou gramatical), textual, discursiva e também normativa, com o objetivo de contribuir para o desenvolvimento de habilidades de leitura/escuta, de produção de textos orais e escritos e de análise e sistematização dos fenômenos linguísticos. (MENDONÇA, 2006, p. 208).

Verifica-se, a partir de Mendonça (2006), que a AL deve envolver não só aspectos sistêmicos da língua, mas gramaticais, textuais e discursivos. Pode-se também constatar que a gramática normativa foi englobada pelas práticas de $\mathrm{AL}$, entretanto, não nos moldes em que era ensinada antes. A ideia não é essa. $O$ professor deve promover a análise dos saberes que o aluno precisa para que amplie suas habilidades sociocomunicativas. Esses saberes precisam ser trabalhados numa perspectiva analítico-reflexiva, direcionados para a compreensão dos sentidos e para o funcionamento do texto. Acerca desse tópico, Bezerra e Reinaldo (2013, p. 81), ao discutirem uma atividade de AL que envolve a noção de artigos, defendem que “[...] se é de seu interesse e há necessidade para o aluno

\footnotetext{
${ }^{5}$ É preciso lembrar que a expressão "análise linguística” também é empregada na acepção de "ato de
} descrever e explicar ou interpretar aspectos da língua” (BEZERRA; REINALDO, 2013, p. 21). 
aprender, cabe ao professor ensinar categorias da tradição e da Linguística moderna e seu funcionamento no texto, que se enquadra em um gênero".

Para esclarecer e encerrar a etapa de definições da AL, segue a visão de Wachowicz (2010, p. 14), que prefere mostrar o que não é AL para, por fim, defini-la:

[...] análise linguística não é levantamento de fatores contextuais que condicionam um texto a ser o que é. Análise linguística não é - no seco tratamento sociopragmático do texto; não é puramente a análise de vozes ideológicas do fio discursivo; e também não é simplesmente conteúdo temático que provoca sua construção argumentativa. É tudo isso voltado à língua. Nesse momento, o professor de língua é um linguista: ele observa, na sua lente investigatória, o dado da língua que faz significação, o dado da língua que faz efeito de sentido e, por conseguinte, que satisfaz a situação comunicativa. No detalhamento desse olhar, a lente de análise requer diferentes perspectivas: fonético-fonológicas, lexicais, morfológicas, sintáticas e semânticas.

A partir de Wachowicz (2010), fica simples entender que uma visão única de gramática não é suficiente para o trabalho de AL. É preciso uma relação de saberes que extrapola o normativismo. É por isso que assumimos, neste artigo, a ideia de gramáticas e ensino, aliadas, aos componentes textuais, discursivos e extralinguísticos.

\section{Alguns fundamentos da AL}

A despeito das recomendações oficiais (BRASIL, 1998, 2000, 2002, 2006) e da literatura na área (GERALDI, 2002 [1984]; ANTUNES, 2003, 2007, 2009, 2014; MENDONÇA, 2006, WACHOWICZ, 2010; KEMIAC E ARAÚJO, 2010; BEZERRA E REINALDO, 2013), o que se verifica, na realidade, é que os pressupostos da $A L$, por motivos variados, ainda não se fazem presentes em sala de aula. É por essa razão que, neste artigo, realiza-se a seguir uma exposição dos vários princípios da AL. Toma-se como fundamento básico a visão interacionista da linguagem, visto que, sem ela, não se pode desenvolver ALs em classe. Outro fato que merece ser lembrado é que, embora apresentados separadamente por uma questão didática, esses princípios só fazem sentido se relacionados e interligados.

Vale salientar, ainda, que, esses fundamentos não estão especificados, em sua totalidade, em uma única obra ou documento. Recorreu-se, para a discussão, a vários estudos ${ }^{6}$, os quais se encontram referenciados ao longo da apresentação dos fundamentos da $\mathrm{AL}$, que seguem nas próximas seções.

\footnotetext{
${ }^{6}$ Kemiac e Araújo (2010) também propõem uma sistematização dos mesmos, no entanto, pretende-se, neste estudo, um aprofundamento e uma ampliação de tópicos necessários e o estabelecimento de uma relação com os tipos de gramática.
} 


\subsection{A AL e a heterogeneidade linguística}

Sabe-se que o Português, como qualquer outra língua, é intrinsecamente heterogêneo e com constantes processos de mudança. Isso significa, portanto, que o Português não é uma unidade estática ou apresenta uma única forma de falar. Entretanto, toda essa heterogeneidade não é confusa ou desordenada, pois é condicionada por variados fatores e segue determinados princípios. Além disso, a heterogeneidade faz parte da natureza linguística e nasce da diversidade dos grupos sociais e das suas relações com a língua. Toda essa complexidade mostra que a língua pode ser considerada um sistema, porém sempre em movimento, reorganizando-se e inserindo-se num ambiente de uso linguístico (FARACO, 2004).

Marcuschi (2003), remetendo a posição de Franchi (1977), afirma que língua é mais que um conjunto de elementos sistemáticos para dizer o mundo, pois se manifesta como uma atividade social e histórica desenvolvida interativamente pelos indivíduos.

Sobre o tema, Koch (2003) defende que a língua é simultaneamente sistema e prática social (propriedades intrínsecas e indissociáveis). Para a autora, a língua é um conjunto de elementos inter-relacionados (níveis morfológico, semântico, sintático, fonológico, etc.) que se realizam em práticas sociais onde ela é construída, assimilada, reconstruída, significada, referenciada, etc. Assim, todos esses elementos que constituem o Português não podem ficar à margem do ensino.

Nesse sentido, os pressupostos da prática de AL corroboram para que essa visão de língua seja posta em ênfase em sala de aula, já que pressupõe reflexões sobre a língua viva e não somente sobre exemplos prontos vindos da gramática normativa. Gil e Simões (2015) [muito bem] argumentam sobre esse fato, afirmando que a AL deve focalizar casos da língua e não exemplos. Segundo as autoras "[... ] a presença de casos possibilita que se parta do emprego da língua para a reflexão linguística” (2015, p. 277), ao contrário do que acontece quando se passam exemplos prontos para a classe.

\subsection{A AL, o texto e a articulação com outras práticas}

Antunes (2014), acerca da gramática em uso na escola, afirma que "a relevância dessa gramática contextualizada está, exatamente, na decisão de não isolar os elementos gramaticais de outros lexicais ou textuais, mas, ao contrário, ver a gramática tecendo, junto com outros constituintes, os sentidos expressos” (ANTUNES, 2014, p. 47).

Assim, o trabalho de reflexão sobre a língua na perspectiva da AL busca a compreensão dos sentidos e a análise dos fatos na articulação textual e discursiva, visto que o estudo isolado de fragmentos é amorfo. Toda essa articulação ocorre quando o sujeito 
usa a língua, por meio de textos orais, escritos e multimodais, nas situações de interação social. É por isso que o trabalho com AL só pode estar relacionado às outras práticas, ou seja, à leitura, à escrita e à oralidade. Nas palavras de Mendonça:

[...] a AL surge como alternativa complementar às práticas de leitura e produção de texto, dado que possibilitaria a reflexão consciente sobre fenômenos gramaticais e textual-discursivos que perpassam os usos linguísticos, seja no momento de ler/escutar, de produzir textos ou de refletir sobre esses mesmos usos da língua. (MENDONÇA, 2006, p. 204).

Em atividades de leitura, visa-se, portanto, não só a compreensão do sentido global, mas observar os recursos linguísticos e extralinguísticos empregados no texto. Esses aspectos podem ser de ordens variadas, ou seja, referentes às diversas dimensões do objeto em foco. Logo, um texto deve ser explorado em variados ângulos e perspectivas, podendo-se discutir fenômenos relacionados ao sistema da língua (questões fonético-fonológicas, morfológicas, sintáticas, por exemplo), à composição discursiva-textual (gênero, objetivo, composição textual, etc.) e aos elementos não-linguísticos (tipo e tamanho de letras, disposição gráfica, imagem, som, cores, entre outros).

Do mesmo modo, no momento em que o indivíduo produz um texto, ele pensa o que escrever e como escrever. Essa é uma atividade epilinguística ${ }^{7}$, ou seja, uma ação reflexiva sobre a própria linguagem, sobre o que está escrevendo ou falando. Essa ação se intensifica quando ocorre a revisão do texto escrito, pois o próprio indivíduo faz AL, busca uma adequação textual ao seu objetivo, recorrendo para isso a mecanismos sintáticos, estratégias argumentativas específicas, entre outros. É uma atividade em que o indivíduo pensa sobre a melhor forma de se expressar na situação em questão, ou seja, segundo sua intenção discursiva, a pessoa organiza, constrói e reformula todo o seu enunciado.

Logo, quando o texto do educando é avaliado, o professor desempenha um papel muito importante, pois pode indicar aspectos a serem aperfeiçoados. ${ }^{8}$ Cabe ao docente, verificar quais são as principais ideias e recursos que precisam de ajustes e, assim, direcionar de forma reflexiva a avaliação ${ }^{9}$ de um texto, contribuindo para o desenvolvimento do aluno. Como aponta Antunes (2014, p. 46), para isso, o professor precisa conduzir à compreensão de como os elementos gramaticais (de qualquer ordem) colaboram na significação do texto. Nas palavras da autora, é preciso, ao ler um texto, compreender o que os

\footnotetext{
7 O epilinguismo será discutido em maiores detalhes na próxima seção.

${ }^{8}$ Esta foi a ideia inicial de AL proposta por Geraldi (2002 [1984]).

9 Ver também Wachowicz (2015).
} 
[...] efeitos de sentido provocam; que funções desempenham; por que acontecem e como acontecem, nessa ou naquela posição; a que pretensões comunicativas respondem e outros aspectos, sempre, vinculados à condição de que estão presentes no texto por conta de alguma função ou de algum efeito de sentido.

É importante salientar que, ao contrário do que muitos docentes pensam, a AL não está restrita à leitura e/ou à escrita de textos (ANTUNES, 2014). A oralidade também pode ser foco de reflexões linguísticas na escola, com o objetivo de trazer à tona, sobretudo, aspectos da gramática internalizada e explicitar normas linguísticas implícitas. Pode também ser um momento profícuo para se discutir oralidade e escrita, formalidade e informalidade, entre outros, e permitir um importante passo para a autonomia do aluno e para o desenvolvimento de suas potencialidades interacionais.

\subsection{A AL e o epilinguismo}

Segundo Geraldi (2002 [1984]), a prática de AL tem que levar a reflexões sobre os fatos linguísticos por meio de atividades epilinguísticas. Entende-se por epilinguismo a prática reflexiva em relação a um texto (escrito, lido, falado e/ou ouvido) e suas operações sobre ele, de forma a explorá-lo em diferentes aspectos e níveis. A atividade epilinguística $^{10}$ diferencia-se da linguística, que consiste, essencialmente, no próprio ato de ler e escrever, e também se distingue da metalinguística, que supõe a capacidade de descrever e falar sobre a linguagem como objeto de estudo.

Para argumentar a favor do epilinguismo na AL, Geraldi baseia-se em Franchi (1991), que afirma que, no trabalho de linguagem, o sujeito já realiza constantemente essas três ações e, assim, as práticas escolares também devem usá-las. Acrescenta-se, portanto, o metalinguismo e o epilinguismo. Esses dois tipos de reflexão - epilinguística e metalinguística -, segundo Bezerra e Reinaldo (2013, p. 38), "possibilitam a adição, aos estudos gramaticais, de novos conteúdos referentes ao texto, correspondendo não apenas à substituição da unidade de análise (da palavra/frase para o texto), mas também a mudanças mais profundas (MENDONÇA, 2006), incluindo contribuições de teorias de gênero".

Em atividades de $\mathrm{AL}$, as ações epilinguísticas permitem operações sobre a linguagem, pois para Franchi (1991, p. 36-37), por meio dela, o sujeito "compara as expressões, transforma-as, experimenta novos modos de construção canônicos ou não, brinca com

${ }^{10}$ Cf. Franchi (1991). 
a linguagem, investe as formas lingüísticas de novas significações”. Operando sobre sua própria língua, o educando vai se tornando ciente dos recursos de que dispõe, bem como busca outras estratégias, potencializando suas habilidades para as diversas atuações sociais. Aliado a isso, as reflexões epilinguísticas podem tomar vida nas produções textuais dos alunos, uma vez que eles interagem através do que produzem.

Sobre isso, Bakhtin (2013), em reflexão sobre a educação russa, também afirma que mais importante que saber analisar os conteúdos gramaticais, é saber empregá-los de modo criativo e crítico em seus próprios textos, ou seja, "na linguagem da vida viva”. Para o estudioso, uma abordagem estilística pode oferecer uma reflexão que conduza o aluno a compreender as diversas possibilidades de uso dos conteúdos gramaticais.

\subsection{A AL e o pensamento indutivo}

Para a discussão da linha de pensamento da $\mathrm{AL}$, dois procedimentos metodológicos merecem atenção. O primeiro deles é o procedimento que leva a descobertas, partindo da manipulação dos dados (indução); o segundo é aquele que prediz uma hipótese e tenta verificá-la (dedução). Uma metodologia dedutiva, portanto, possui um caráter mais específico, como se buscasse algo que já está no dado, ao passo que uma metodologia indutiva, dá espaço ao novo, a descobertas, a pesquisa, a organização, de certa forma, livre, em reação à realidade do que se busca (GALVÃO, 2007).

Relacionando esses caminhos ao trabalho escolar, verifica-se que o sujeito se depara, constantemente, com essas duas vertentes metodológicas no seu processo de ensino-aprendizagem. Uma, que visa ao conteúdo estruturado, apenas objetivando seu fim, a assimilação da regra (dedução); e outra, que permite uma reflexão por parte do sujeito e que fornece arcabouços de aprendizagem significativa, de construção de conhecimento e de organização sistemática, proporcionando uma reflexão acerca do processo de aprendizagem (indução).

É por isso que um dos pilares da prática de AL é a reflexão linguística e o pensamento indutivo, "[.. ] as atividades precisam conduzir, indutivamente, o aluno à construção e sistematização de saberes por meio de ações epilinguísticas” (GOMES; SOUZA, 2015, p. 20). Também Kemiac e Araújo (2010, p. 50) destacam esse princípio da AL, afirmando que "a metodologia subjacente ao ensino de AL é, portanto, indutiva, partindo da vivência, da observação de casos particulares para a formulação de regras gerais”.

Para que essa metodologia seja posta em prática no processo da AL, é necessário que o docente promova em suas aulas a possibilidade de o estudante vivenciar análises e reflexões por meio da observação da língua em suas diversas realizações. Dessa maneira, 
ao contrário de uma aprendizagem mecânica e obscura, baseada em exemplos prontos, conduz-se uma compreensão mais autêntica do conhecimento a ser adquirido.

Nessa perspectiva, a participação do sujeito ganha ênfase, à medida que ele vai observando as diversas regras gramaticais possíveis, além de compreendê-las e sistematizá-las. Também as diferentes variedades da língua entram em jogo, pois o corpus de análise é real. Assim, o aluno, que já intuitivamente emprega a indução em situações cotidianas, também a empregará cientificamente, investigando as regras das diferentes possibilidades de emprego linguístico, ampliando, assim, os recursos para os seus próprios usos.

Sobre essa questão da observação dos dados, os PCNs (BRASIL, 1998) sugerem até mesmo que docentes e alunos coletem a língua em uso e construam um corpus $^{11}$ linguístico para a investigação em classe. De posse dos dados, o discente pode manipulá-lo de modo a perceber as regularidades existentes. Essa atividade pode contribuir, sobremaneira, para a compreensão de características da língua falada brasileira, alvo de tantos julgamentos, críticas e preconceitos. Entretanto, os textos escritos não podem ser negligenciados, especialmente pelo fato de que a escola necessita capacitar o aluno para a escrita em ambientes formais. Assim, a indução também objetiva permear reflexões sobre a produção escrita, levando o discente a conclusões sobre os aspectos inerentes a esse contexto de uso.

\subsection{A AL e a sistematização/categorização dos conhecimentos obtidos e novos usos}

Uma vez realizadas as atividades epilinguísticas de modo indutivo, é interessante que o professor conduza uma sistematização dos principais resultados obtidos em uma atividade de AL. Outrossim, quando se fala em sistematização como uma das etapas da AL, pensa-se então em a partir de uma reflexão sobre a língua real (epilinguismo) por meio de procedimentos indutivos (observação dos dados) para se chegar a organização dos saberes obtidos. Sobre esse princípio, Kemiac e Araújo (2010, p. 51) afirmam que "[...] o trabalho com AL deve, necessariamente, culminar com uma sistematização clara e consistente $[\ldots . . . "$

Numa interpretação mais informal, é possível afirmar que sistematizar é organizar, ordenar, resumir. Contudo, no campo educacional, a noção de sistematização é muito mais complexa, pois não remete a uma mera organização do que se estudou. Visa-se, com a sistematização, a levar a uma reflexão, seguida de uma reelaboração dos conhecimentos observados. Na visão de Souza (1997), a sistematização é mais que uma organização de dados, é um conjunto de práticas e conceitos que propiciam a reflexão e a reelaboração

\footnotetext{
${ }^{11}$ Compreende-se que esse corpus deve ser constituído, é claro, da língua viva e variada.
} 
das ideias, a partir da vivência com a realidade. Observa-se, assim, que a sistematização construa um novo sentido e promova uma mudança, um movimento, uma transformação no indivíduo por meio da experiência vivida.

É exatamente isso que se espera com a sistematização em práticas de AL na escola. Muito mais do que "ter a posse" ou síntese do conhecimento em foco, aspira-se a que o aluno reelabore suas compreensões sobre o Português e reconheça os saberes obtidos como estratégias ou mecanismos linguísticos a serem empregados em futuras situações de uso social da língua.

\subsection{Uma nota sobre o metalinguismo e as nomenclaturas}

Atividades de metalinguagem constituem uma questão bastante polêmica no contexto escolar, devido ao fato de terem sido, por um longo tempo, o centro das aulas de língua materna (ANTUNES, 2009). É necessário, entretanto, destacar que a sua exclusão radical não resolve nada. Muitas vezes, para se tratar de um fato da linguagem é preciso atribuir-lhe um nome, assim como acontece com fenômenos estudados em outras áreas.

Atualmente, assume-se que a metalinguagem não seja o foco das aulas, ou seja, não se encontra sentido em atividades exclusivas de classificação e ou de definição. Exercícios com ênfase somente metalinguística, isolados de observação e uso da língua não interessam e não desenvolvem o tato reflexivo sobre a própria língua viva e suas possibilidades de usos. $\mathrm{O}$ que se propõe hoje são atividades reflexivas sobre a língua e a nomenclatura e a metalinguagem, por exemplo, só entram em cena se forem necessárias para o trato do fenômeno ou então em atividades de sistematização (sobretudo considerando a etapa escolar do estudante).

Geraldi, já em 1984 (2002 [1984]), destaca que é interessante que exista um equilíbrio entre atividades de leitura, escrita, oralidade e AL em sala de aula. A AL, para o autor, compreende o estudante não só como usuário, mas também como analista da língua, desempenhando, para tanto, reflexões epilinguísticas (centradas no uso dos recursos expressivos em função das atividades linguísticas) e metalinguísticas (elaborando noções com as quais se torna possível a categorização dos recursos estudados).

\section{Considerações Finais}

Muitos dos problemas existentes com o ensino-aprendizagem de Português decorrem de uma compreensão equivocada sobre a língua. A língua "é um ato humano, social, político, histórico, ideológico, que tem repercussão na vida de todas as pessoas” 
(ANTUNES, 2007, p. 21). Assim, o primeiro aspecto a ser assumido pelo docente é que não se pode confundir língua com gramática inerte, pensando que esse domínio gramatical é o principal pré-requisito para se estudar o Português na escola.

Uma outra questão a ser considerada é sobre o termo gramática. Não se pode acreditar que apenas um único tipo de gramática (a normativa tradicional) está relacionado ao ensino de língua materna. Isso porque o ensino voltado apenas para os fatos formais retratados na abordagem normativo-prescritiva desvincula o aluno dos propósitos reais da língua, ou seja, da interação social. As práticas interativas são heterogêneas, variadas e, essencialmente, dinâmicas. Uma gramática que dá valor apenas a padrões ou modelos não dá conta dessa realidade linguística. Logo, outras concepções de gramática podem ser levadas em conta quando se fala em ensino de língua. Nesse artigo, foram enfatizadas a gramática internalizada, a descritiva e a normativa (em necessidades específicas). No entanto, todas essas gramáticas só ganham sentido se estudadas em usos verídicos, ou seja, em textos. Isso porque todo texto contém, além dos seus aspectos discursivos e contextuais, uma materialidade linguística sonora ou escrita e a prática escolar deve oportunizar análises de tais recursos. Sugere-se, desse modo, para o trabalho escolar, as articulações teórico-metodológicas da $\mathrm{AL}$, que são capazes de considerar as interrelações discursivas, pragmáticas, semânticas, morfossintáticas, fonético-fonológicas, visuais, sonoras que são próprias dos textos (verbais ou multimodais).

Sabe-se, contudo, que um ensino reflexivo da língua, com base no que foi discutido aqui (perspectiva da $\mathrm{AL}$ ), não é uma tarefa fácil, por diferentes razões, entre as quais se destacam: (i) a AL pressupõe um professor-pesquisador, que estude e entenda as diferentes dimensões do objeto de estudo (a língua), além do domínio dos próprios fundamentos que subjazem a prática de $\mathrm{AL}$; (ii) o docente é que precisa preparar suas próprias aulas já que muitos materiais didáticos disponíveis no cenário escolar ainda não se encaixam nos fundamentos da AL (embora muitos manuais afirmem que se enquadram). Enfim, como se vê, uma mudança do panorama das aulas de língua materna ainda demanda tempo, trabalho e, sobretudo, novas pesquisas. Portanto, embora o tema "ensino de gramática” pareça um assunto já amplamente debatido, na verdade, não o é. É preciso sim falar de gramática e ensino.

\section{Referências}

ANTUNES, I. Aula de português: encontro e interação. São Paulo: Parábola, 2003.

ANTUNES, I. Muito Além da Gramática: por ensino de línguas sem pedras no caminho. São Paulo: Parábola Editorial, 2007. 
ANTUNES, I. Língua, texto e ensino: outra escola possível. 2. ed. São Paulo: Parábola Editorial, 2009.

ANTUNES, I. Gramática Contextualizada: limpando “o pó das ideias simples”. São Paulo: Parábola Editorial, 2014.

BEZERRA, M. A.; REINALDO, M. A. Análise Linguística: afinal, a que se refere? São Paulo: Cortez, 2013.

BRASIL. Parâmetros Curriculares Nacionais: terceiro e quarto ciclos do Ensino Fundamental (Língua Portuguesa). Brasília: Ministério da Educação, Secretaria de Educação Básica, 1998.

BRASIL. Parâmetros Curriculares Nacionais. Brasília: Ministério da Educação, Secretaria de Educação Básica, 2000.

BRASIL. Complemento aos Parâmetros Curriculares Nacionais. Brasília: Ministério da Educação, Secretaria de Educação Básica, 2002.

BRASIL. Orientações Curriculares para o Ensino Médio: linguagens, códigos e suas tecnologias. Brasília: Ministério da Educação, Secretaria de Educação Básica, 2006.

BAKHTIN, M. Marxismo e Filosofia da Linguagem. Tradução de Michel Lahud e Yara F. Vieira. São Paulo: Hucitec, 2006.

BAKHTIN, M. Questões de Estilística no Ensino da Língua. Tradução de Sheila Grillo e Ekaterina V. Américo. São Paulo: Editora 34, 2013.

FARACO, C. A. Norma-Padrão brasileira: desembaraçando alguns nós. In: BAGNO, M. (Org.). Lingüística da Norma. São Paulo: Loyola, 2004.

FRANCHI, C. Linguagem, Atividade Constitutiva. Cadernos de Estudos Linguísticos. Campinas, v. 1, n. 22, p. 9-41, 1977.

FRANCHI, C. Criatividade e Gramática. São Paulo: SE/CENP, 1991, p. 7-37.

GALVÃO, R. C. S. Francis Bacon: teoria, método e contribuições para a educação. Revista Internacional Interdisciplinar - InterThesis, Florianópolis, v. 4, n. 2, p. 32- 41, jul./ dez. 2007.

GERALDI, J. W. (Org.). O Texto na Sala de Aula. São Paulo: Ática, 2002.

GIL, M; SIMÕES, J. Casos e Exemplos na Prática Escolar de Reflexão Linguística. In: RBLA, Belo Horizonte, v. 15, n. 1, p. 261-279, 2015.

GOMES, A, R.; SOUZA, S. Os Módulos da Sequência Didática e a prática de Análise Linguística: relações facilitadoras. Con(Textos) Linguísticos, Vitória, v.9, n.14, p. 8-22, 2015.

GÖRSKI, E; MOURA, H. Estudos Gramaticais. Florianópolis: DLLV/UFSC, 2011.

KEMIAC, L.; ARAÚJO, D. Princípios subjacentes à literatura sobre Análise Linguística. Revista Leia Escola, Campina Grande, v. 10, p. 45-58, 2010.

KOCH, I. O Texto e a Construção dos Sentidos. 7. ed. São Paulo: Contexto, 2003. 
MARCUSCHI, L. A. Da fala para escrita: atividades de retextualização. 4 ed. São Paulo: Cortez, 2003.

MENDONÇA, M. Análise Linguística no Ensino Médio: um novo olhar, um outro objeto. In: BUNZEN, C; MENDONÇA, M. Português no Ensino Médio e Formação do Professor. São Paulo: Parábola, 2006.

POSSENTI, S. Por que (não) ensinar Gramática na Escola. Campinas: Mercado de Letras, 1996.

SOUZA, J. F. Sistematização da Experiência por seus Próprios Sujeitos. In: Tópicos Educacionais. Recife-PE: UFPE, Centro de Educação, v. 15, n. 1/3, 1997.

TRAVAGLIA, L. C. Gramática e Interação: uma proposta para o ensino de gramática. 13. ed. São Paulo: Cortez, 2009.

WACHOWICZ, T. Análise Linguística nos Gêneros Textuais. Curitiba: Ibpex, 2010.

WACHOWICZ, T. Avaliação de Textos na Escola. Curitiba: Intersaberes, 2015.

Data de submissão: 03/07/2017

Data de aceite: $13 / 12 / 2017$ 